\section{NCCN Welcomes 2 New Member Institutions}

\author{
Robert W. Carlson, MD
}

The NCCN Board of Directors and Headquarters staff last year completed a strategic planning process that culminated in November 2012 with the adoption by the NCCN Board of Directors of a 5-year Strategic Plan for NCCN. The guiding force behind the Strategic Plan was our new Mission Statement:

"Our Mission as an alliance of leading cancer centers devoted to patient care, research, and education is to improve the quality, effectiveness, and efficiency of cancer care so that patients can live better lives."

The full strategic plan outlines in detail the NCCN's framework for furthering that Mission and will undoubtedly be the subject of future commentaries and articles in JNCCN as NCCN moves forward.

One of the objectives of the strategic plan is the measured and intentional expansion in the number of NCCN Member Institutions over the next 5 years. Two new member institutions that bring substantial strength to NCCN, the University of Colorado Cancer Center and the University of California San Diego Moores Cancer Center, were elected to membership by the NCCN Board of Directors in early March. Both institutions are NCI-designated comprehensive cancer centers, and both have strong patient care, research, and education programs. Both have strong basic science, translational, and clinical research programs exceeding $\$ 100$ million in direct funding. UC San Diego Moores Cancer Center is the clinical hub for 10 scientific centers in the San Diego area and has more than 600 biotech companies in their region that serve to drive new agents to patient care. The University of Colorado Cancer Center has 9 participating institutions, and the University of Colorado Hospital has been ranked number 1 nationally for 2 years in a row among academic hospitals for quality and patient safety. The University of Colorado Cancer Center catchment area has a large population of Native Americans and UC San Diego Moores Cancer Center has a large Hispanic population, which bring further ethnic diversity and strength to the NCCN programs.

Both new Member Institutions were welcomed during the $18^{\text {th }}$ Annual NCCN Conference in March. All of us at NCCN add our welcome to these 2 new member institutions, which bring NCCN membership to 23 leading cancer centers that are defining and advancing high-quality, high-value cancer care.

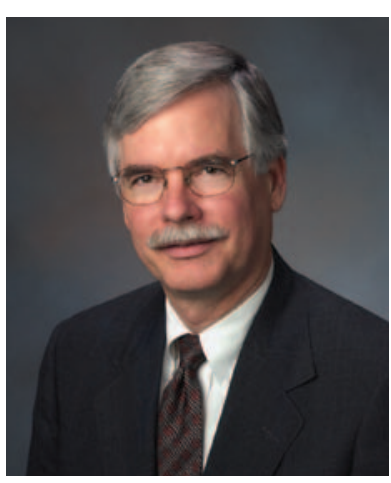

Robert W. Carlson, MD

Robert W. Carlson, MD, joined NCCN as CEO in January 2013 after numerous leadership positions, including chair of the NCCN Breast Cancer Panel and several NCCN Task Forces. He has also been a member of the NCCN Breast Cancer Risk Reduction Panel, Breast Cancer Disease-Specific Executive Committee, CME Advisory Committee, Guidelines Steering Committee, and Board of Directors. Previously, and during the writing of this commentary, Dr. Carlson was Professor of Medicine in the Division of Oncology and Stanford Medical Informatics at Stanford University Medical Center. Dr. Carlson received his medical degree from Stanford University Medical School and completed his internship and junior residency in internal medicine at Barnes Hospital Group in St. Louis. He returned to Stanford for his senior residency and postdoctoral fellowship in medical oncology. Dr. Carlson is board certified in internal medicine and holds a subspecialty certification in medical oncology. Dr. Carlson is a member of several medical societies. He lectures extensively and has authored or co-authored over 130 articles, abstracts, and book chapters. $\mathrm{He}$ is also Associate Editor of Oncology and JNCCN.

The ideas and viewpoints expressed in this editorial are those of the author and do not necessarily represent any policy, position, or program of NCCN. 